\title{
Estimation of prediction error variances via Monte Carlo sampling methods using different formulations of the prediction error variance
}

\author{
John M Hickey*1,2,3, Roel F Veerkamp ${ }^{1}$, Mario PL Calus ${ }^{1}$, Han A Mulder ${ }^{1}$ and \\ Robin Thompson $4,5,6$
}

\begin{abstract}
Address: ${ }^{1}$ Animal Breeding and Genomics Centre, Animal Sciences Group, PO Box 65, 8200 AB, Lelystad, The Netherlands, ${ }^{2}$ Grange Beef Research Centre, Teagasc, Dunsany, Co. Meath, Ireland, ${ }^{3}$ School of Agriculture, Food and Veterinary Medicine, College of Life Sciences, University College Dublin, Belfield, Dublin 4, Ireland, ${ }^{4}$ School of Mathematical Sciences, Queen Mary, University of London, Mile End Road, London E1 4NS, UK, ${ }^{5}$ Centre for Mathematical and Computational Biology, Rothamsted Research, Harpenden AL5 2JQ, UK and ${ }^{6}$ Department of Biomathematics and Bioinformatics, Rothamsted Research, Harpenden AL5 2JQ, UK
\end{abstract}

Email: John M Hickey* - john.hickey@une.edu.au; Roel F Veerkamp - roel.veerkamp@wur.nl; Mario PL Calus - mario.calus@wur.nl; Han A Mulder - herman.mulder@wur.nl; Robin Thompson - robin.thompson@bbsrc.ac.uk

* Corresponding author

Published: 9 February 2009

Genetics Selection Evolution 2009, 41:23 doi:10.1 186/1297-9686-4I-23

This article is available from: http://www.gsejournal.org/content/4I/I/23

(C) 2009 Hickey et al; licensee BioMed Central Ltd.

This is an Open Access article distributed under the terms of the Creative Commons Attribution License (http://creativecommons.org/licenses/by/2.0), which permits unrestricted use, distribution, and reproduction in any medium, provided the original work is properly cited.

\begin{abstract}
Calculation of the exact prediction error variance covariance matrix is often computationally too demanding, which limits its application in REML algorithms, the calculation of accuracies of estimated breeding values and the control of variance of response to selection. Alternatively Monte Carlo sampling can be used to calculate approximations of the prediction error variance, which converge to the true values if enough samples are used. However, in practical situations the number of samples, which are computationally feasible, is limited. The objective of this study was to compare the convergence rate of different formulations of the prediction error variance calculated using Monte Carlo sampling. Four of these formulations were published, four were corresponding alternative versions, and two were derived as part of this study. The different formulations had different convergence rates and these were shown to depend on the number of samples and on the level of prediction error variance. Four formulations were competitive and these made use of information on either the variance of the estimated breeding value and on the variance of the true breeding value minus the estimated breeding value or on the covariance between the true and estimated breeding values.
\end{abstract}

\section{Introduction}

In quantitative genetics the prediction error variance-covariance matrix is central to the calculation of accuracies of estimated breeding values ( $\hat{\mathbf{u}}$ ) [e.g. [1]], to REML algorithms for the estimation of variance components [2], to methods which restrict the variance of response to selec- tion [3], and can be used to explore trends in Mendelian sampling deviations over time [4]. The mixed model equations (MME) for most national genetic evaluations range from 100,000 to $20,000,000$ equations and inversion of systems of equations of this size is generally not possible because of their magnitude or because of loss of 
numerical precision [5]. Methods that approximate the prediction error variances (PEV) and calculate the accuracy of $\hat{\mathrm{u}}$ provide biased estimates in some circumstances by ignoring certain information [e.g. [6]]. Variance components upon which genetic evaluations of large populations are based are generally estimated using reduced data sets. The use of reduced data sets may create bias in the estimates as REML only provides unbiased estimates of variance components when all the data on which selection has taken place is included in the analysis [7]. Variance of response to selection is generally not controlled in breeding programs although it might be a risk to them [3].

Approximations of the PEV without needing to invert the coefficient matrix or to delete data, can be obtained by comparing Monte Carlo samples of the data and successive solutions of the mixed model equations of this data.

However different formulations have been presented to approximate the PEV in this way [8-11]. Approximations of the PEV using these formulations converge to the exact PEV ( PEV $\left._{\text {exact }}\right)$ as the number of Monte Carlo samples increases, but the number of samples is generally limited by computational requirements in practice [e.g. [12]]. Also, differences in the rates of convergence have been shown to depend on the level of $\mathrm{PEV}_{\text {exact }}$ for a given genetic variance $\left(\sigma_{g}^{2}\right)[10]$. Consequently, when finding the optimal number of iterations required, both the different formulations, and the level of $\mathrm{PEV}_{\text {exact }}$ need to be taken into account. Some of the formulations are weighted averages of other formulations, with the weighting depending on the sampling variances of these. Garcia-Cortes et al. [10] use asymptotic approximations of these sampling variances. Alternative weighting strategies could use empirically approximated sampling variances based on independent replicates of samples or using leave-one-out Jackknife procedures [13,14].

The objective of this study was to compare the convergence to $\mathrm{PEV}_{\text {exact }}$ of ten different formulations of the PEV, using simulations based on data and pedigree from a commercial population containing animals with different levels of PEV and using different numbers of samples $(n=$ $50,100, \ldots, 950,1000)$. Four of the formulations were previously published, four were alternative versions of these, and two were derived as part of this study.

\section{Methods}

\section{Monte Carlo sampling procedure for calculating PEV}

The Monte Carlo sampling procedure for calculating the sampled PEV has been described extensively elsewhere for single breed [8-10] and multiple breed scenarios [12]. Assuming a simple additive genetic animal model without genetic groups $\mathbf{y}=\mathbf{X b}+\mathbf{Z u}+\mathbf{e}$, where the distribution of random variables is $\mathbf{y} \sim N(\mathrm{Xb}, \mathrm{ZGZ}+\mathrm{R}), \mathbf{u} \sim N(\mathbf{0}, \mathrm{G})$, and $\mathrm{e} \sim N(\mathbf{0}, \mathbf{R})$, the three steps involved in calculating the sampled PEV are as follows: 1 . Simulate $n$ samples of $\mathbf{y}$ and $\mathbf{u}$ using the pedigree and the distributions of the original data, modified to account for the fact that the expectation of $\mathbf{X b}$ does not affect the distribution of random variables $[15,16]$ thus the samples of $y$ can be simulated using random normal deviates from $N(\mathbf{0}, \mathbf{Z G Z}+\mathbf{R})$ instead of $N(\mathbf{X b}, \mathbf{Z G Z}+\mathbf{R})$. 2. Set up and solve the mixed model equations for the data set using the $n$ simulated samples of $y$ instead of the true $y$. This accounts for the fixed effects structure of the real data. 3. Calculate the sampled PEV for some formulation.

\section{Formulations of PEV}

Ten formulations of the sampled PEV are shown in Table 1. The first three formulations $\left(\mathrm{PEV}_{\mathrm{GC} 1}, \mathrm{PEV}_{\mathrm{GC} 2}\right.$, and $\mathrm{PEV}_{\mathrm{GC} 3}$ ) were outlined by Garcia-Cortes et al. [10] and the fourth formulation $\left(\mathrm{PEV}_{\mathrm{FL}}\right)$ was outlined by Fouilloux and Laloë [8]. $\mathrm{PEV}_{\mathrm{AF} 1}, \mathrm{PEV}_{\mathrm{AF} 2}, \mathrm{PEV}_{\mathrm{AF} 3}$, and $\mathrm{PEV}_{\mathrm{AF} 4}$ are alternative versions of these formulations, which rescale the formulations from the Var $(\mathrm{u})$ and to the $\sigma_{g}^{2}$ in order to account for the effects of sampling on the $\operatorname{Var}(\mathrm{u})$. Two new formulations of the sampled PEV $\left(\mathrm{PEV}_{\mathrm{NF} 1}\right.$, and $\mathrm{PEV}_{\mathrm{NF} 2}$ ) are also given in Table 1. The ten formulations differ from each other in the way in which they compare information relating to the $\operatorname{Var}(\mathrm{u})$, the $\operatorname{Var}(\hat{\mathrm{u}})$, the $\operatorname{Var}(\mathrm{u}$ - $\hat{u})$, or the $\operatorname{Cov}(\mathrm{u}, \hat{\mathrm{u}})$.

\section{Approximation of sampling variance of PEV}

Formulae, based on Taylor series approximations, to predict the asymptotic sampling variances for each of the ten formulations of sampled PEV at different levels of $\mathrm{PEV}_{\text {exact }}$ are given in Table 1. The sampling variance can also be approximated stochastically using a number (e.g. 100) of independent replicates of the $n$ samples or by applying a leave-one-out Jackknife $[13,14]$ to the $n$ samples.

\section{Application to test data set Data and model}

A data set containing 32,128 purebred Limousin animals with records for a trait (height) and a corresponding pedigree of 50,435 animals was extracted from the Irish Cattle Breeding Federation database. In the simulations the trait 
Table I: Previously published, alternative, and new formulations of the prediction error variance for a random effect $u$ with $\sigma_{g}^{2}$, the assumptions pertinent to each formulation, the information used in each formulation, and the asymptotic sampling variances of each formulation

\begin{tabular}{|c|c|c|c|}
\hline Formulation & Assumptions & Uses information on & Asymptotic sampling variance \\
\hline $\mathrm{IPEV}_{\mathrm{GCI}}=\sigma_{\mathrm{g}}^{2}-\operatorname{Var}(\hat{\mathrm{u}})$ & $\begin{array}{l}\operatorname{Cov}(\mathrm{u}, \hat{\mathrm{u}})=\operatorname{Var}(\hat{\mathrm{u}}) \\
\operatorname{Var}(\mathrm{u})=\sigma_{\mathrm{g}}^{2}\end{array}$ & $\mathrm{u}$ & $2 r^{4} \sigma_{\mathrm{g}}^{4} / n$ \\
\hline${ }^{2} \mathrm{PEV}_{\mathrm{GC} 2}=\operatorname{Var}(\mathrm{u}-\hat{\mathrm{u}})$ & $\begin{array}{l}{ }^{1} \operatorname{Cov}(\mathrm{u}, \hat{\mathrm{u}}) \neq l=\operatorname{Var}(\hat{\mathrm{u}}) \\
\operatorname{Var}(\mathrm{u})=\sigma_{\mathrm{g}}^{2}\end{array}$ & $\mathrm{u}-\hat{\mathrm{u}}$ & $2\left(1-r^{2}\right)^{2} \sigma_{\mathrm{g}}^{4} / n$ \\
\hline${ }^{3} \mathrm{PEV}_{\mathrm{GC} 3}=\frac{\left[\frac{\mathrm{PEV}_{\mathrm{GC} 1}}{\operatorname{Var}\left(\mathrm{PEV}_{\mathrm{GC} 1}\right)}\right]+\left[\frac{\mathrm{PEV}_{\mathrm{GC} 2}}{\operatorname{Var}\left(\mathrm{PEV}_{\mathrm{GC} 2}\right)}\right]}{\frac{1}{\operatorname{Var}\left(\mathrm{PEV}_{\mathrm{GC} 1}\right)}+\frac{1}{\operatorname{Var}\left(\mathrm{PEV}_{\mathrm{GC} 2}\right)}}$ & $\begin{array}{l}\operatorname{Cov}(\mathrm{u}-\hat{\mathrm{u}}, \hat{\mathrm{u}})=0 \\
\operatorname{Var}(\mathrm{u})=\sigma_{\mathrm{g}}^{2}\end{array}$ & $\hat{\mathrm{u}}, \mathrm{u}-\hat{\mathrm{u}}$ & $\left\{\left[2 r^{4}\left(I-r^{2}\right)^{2}\right] /\left[\left(I-r^{2}\right)^{2}+r^{4}\right]\right\} \sigma_{\mathrm{g}}^{4} / n$ \\
\hline${ }^{4} \mathrm{PEV} \mathrm{FL}_{\mathrm{FL}}=\sigma_{\mathrm{g}}^{2}-\operatorname{Cov}(\mathrm{u}, \hat{\mathrm{u}})$ & $\begin{array}{l}\operatorname{Cov}(\mathrm{u}, \hat{\mathrm{u}})=\operatorname{Var}(\hat{\mathrm{u}}) \\
\operatorname{Var}(\mathrm{u})=\sigma_{\mathrm{g}}^{2}\end{array}$ & $\operatorname{Cov}(\mathrm{u}, \hat{\mathrm{u}})$ & $r^{2}\left(I+r^{2}\right) \sigma_{g}^{2} / n$ \\
\hline${ }^{5} \mathrm{PEV}_{\mathrm{AFI}}=\sigma_{\mathrm{g}}^{2}-[\operatorname{Var}(\hat{\mathrm{u}}) / \operatorname{Var}(\mathrm{u})] \sigma_{\mathrm{g}}^{2}$ & $\begin{array}{l}\operatorname{Cov}(\mathrm{u}, \hat{\mathrm{u}})=\operatorname{Var}(\hat{\mathrm{u}}) \\
\operatorname{Var}(\mathrm{u}) \neq \sigma_{\mathrm{g}}^{2}\end{array}$ & $\hat{\mathrm{u}}, \mathrm{u}$ & $4 r^{4}\left(1-r^{2}\right) \sigma_{g}^{4} / n$ \\
\hline${ }^{6} \mathrm{PEV}_{\mathrm{AF2} 2}=[\operatorname{Var}(\mathrm{u}-\hat{\mathrm{u}}) / \operatorname{Var}(\mathrm{u})] \sigma_{\mathrm{g}}^{2}$ & $\begin{array}{l}{ }^{1} \operatorname{Cov}(\mathrm{u}, \hat{\mathrm{u}}) \neq l=\operatorname{Var}(\hat{\mathrm{u}}) \\
\operatorname{Var}(\mathrm{u}) \neq \sigma_{\mathrm{g}}^{2}\end{array}$ & $\mathrm{u}-\hat{\mathrm{u}}, \mathrm{u}$ & $4 r^{2}\left(I-r^{2}\right)^{2} \sigma_{g}^{4} / n$ \\
\hline $7 \mathrm{PEV}_{\mathrm{AF} 3}=\frac{\left[\frac{\mathrm{PEV}_{\mathrm{AF} 1}}{\operatorname{Var}\left(\mathrm{PEV}_{\mathrm{AF} 1}\right)}\right]+\left[\frac{\mathrm{PEV}_{\mathrm{AF} 2}}{\operatorname{Var}\left(\mathrm{PEV}_{\mathrm{AF} 2}\right)}\right]}{\frac{1}{\operatorname{Var}\left(\mathrm{PEV}_{\mathrm{AF} 1}\right)}+\frac{1}{\operatorname{Var}\left(\mathrm{PEV}_{\mathrm{AF} 2}\right)}}$ & $\begin{array}{l}\operatorname{Cov}(\mathrm{u}-\hat{\mathrm{u}}, \hat{\mathrm{u}})=0 \\
\operatorname{Var}(\mathrm{u}) \neq \sigma_{\mathrm{g}}^{2}\end{array}$ & $\hat{\mathrm{u}}, \mathrm{u}-\hat{\mathrm{u}}, \mathrm{u}$ & $4 r^{4}\left(I-r^{2}\right)^{2} \sigma_{g}^{4} / n$ \\
\hline${ }^{8} \mathrm{PEV}_{\mathrm{AF} 4}=\sigma_{\mathrm{g}}^{2}-[\operatorname{Cov}(\mathrm{u}, \hat{\mathrm{u}}) / \operatorname{Var}(\mathrm{u})] \sigma_{\mathrm{g}}^{2}$ & $\begin{array}{l}\operatorname{Cov}(\mathrm{u}, \hat{\mathrm{u}})=\operatorname{Var}(\hat{\mathrm{u}}) \\
\operatorname{Var}(\mathrm{u}) \neq \sigma_{\mathrm{g}}^{2}\end{array}$ & $\operatorname{Cov}(\mathrm{u}, \hat{\mathrm{u}}), \mathrm{u}$ & $r^{2}\left(1-r^{2}\right) \sigma_{g}^{2} / n$ \\
\hline 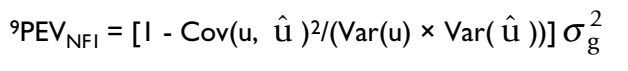 & & & $4 r^{2}\left(I-r^{2}\right)^{2} \sigma_{g}^{2} / n$ \\
\hline${ }^{10} \mathrm{PEV}_{\mathrm{NF} 2}=\left\{\operatorname{Var}(\mathrm{u}-\hat{\mathrm{u}}) /[\operatorname{Var}(\hat{\mathrm{u}})+\operatorname{Var}(\mathrm{u}-\hat{\mathrm{u}}]\} \sigma_{\mathrm{g}}^{2}\right.$ & $\operatorname{Cov}(u-\hat{u}, \hat{u})=0$ & $\hat{\mathrm{u}}$ and $\mathrm{u}-\hat{\mathrm{u}}$ & $4 r^{4}\left(I-r^{2}\right)^{2} \sigma_{g}^{4} / n$ \\
\hline
\end{tabular}

'Garcia-Cortes et al. (1995) formulation I

${ }^{2}$ Garcia-Cortes et al. (1995) formulation 2

${ }^{3}$ Garcia-Cortes et al. (1995) formulation 3

${ }^{4}$ Fouilloux and Laloë (2001) formulation

${ }^{5}$ Corrects $\mathrm{PEV}_{\mathrm{GCl}}$ for $\operatorname{Var}(\mathrm{u}) \neq \sigma_{\mathrm{g}}^{2}$ and corresponds to Lidauer et al. (2007)

${ }^{6}$ Corrects $\operatorname{PEV}_{\mathrm{GC} 2}$ for $\operatorname{Var}(\mathrm{u}) \neq \sigma_{\mathrm{g}}^{2}$

${ }^{7}$ Corrects $\operatorname{PEV}_{\mathrm{GC} 3}$ for $\operatorname{Var}(\mathrm{u}) \neq \sigma_{\mathrm{g}}^{2}$

${ }^{8}$ Corrects $\mathrm{PEV}_{\mathrm{FL}}$ for $\operatorname{Var}(\mathrm{u}) \neq \sigma_{\mathrm{g}}^{2}$

${ }^{9}$ Based on the classical formulation of the accuracy of an EBV

${ }^{10}$ Implicitly weighs information on $\operatorname{Var}(\hat{\mathrm{u}})$ and $\operatorname{Var}(\mathrm{u}, \hat{\mathrm{u}})$ and corrects for $\operatorname{Var}(\mathrm{u}) \neq \sigma_{\mathrm{g}}^{2}$

"No assumption made about the relationship between $\operatorname{Var}(\hat{\mathrm{u}})$ and $\operatorname{Cov}(\mathrm{u}, \hat{\mathrm{u}})$ 
was assumed to have a $\sigma_{g}^{2}$ of 1.0 and residual variance $\sigma_{\mathrm{r}}^{2}$ of 3.0. Fixed effects were contemporary group, technician who scored the animal, parity of dam, age of animal at scoring and sex.

\section{Calculation of exact PEV}

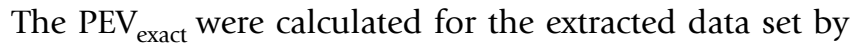
setting up and solving the MME, with fixed effects of contemporary group, technician who scored the animal, parity of dam, and a second order polynomial of age of animal at scoring nested within sex, and random animal and residual effects, using the BLUP option in ASReml [17] which fully inverts the left hand side of the MME.

\section{Sampled PEV}

Following the Monte Carlo sampling procedure described above, 100,000 samples of the extracted data set were simulated assuming a $\sigma_{g}^{2}$ of 1.0 and $\sigma_{r}^{2}$ of 3.0. For each of the simulated data sets MME, using the same design matrix (X) as used when estimating the $\mathrm{PEV}_{\text {exact}}$, were set up and solved using MiX99 [18]. The sampled PEV of the $\hat{\mathrm{u}}$ for each animal in the pedigree was approximated using the formulations of the sampled PEV described in Table 1 using $n$ samples $(n=50,100, \ldots, 950,1000)$.

Stochastic approximations of the sampling variance of the sampled PEV were calculated using 100 independent replicates of the $n$ samples, and using the leave-one-out Jackknife on $n$ samples, for the different formulations, with the exception of $\mathrm{PEV}_{\mathrm{GC} 3}$ and $\mathrm{PEV}_{\mathrm{AF} 3}$. To calculate the sampling variance for $\mathrm{PEV}_{\mathrm{GC} 3}$ and $\mathrm{PEV}_{\mathrm{AF} 3}$ using $n$ independent replicates would have required more than 100,000 samples (due to the need to generate sampling variances of component formulations) generated for this study so therefore these were not considered. Asymptotic sampling variances for all ten formulations were calculated using the formulae in Table 1.

\section{Alternative weighting strategies}

Of the formulations presented in Table $1, \mathrm{PEV}_{\mathrm{GC} 3}$ and $\mathrm{PEV}_{\mathrm{AF} 3}$ are weighted averages of $\mathrm{PEV}_{\mathrm{GC} 1}$ and $\mathrm{PEV}_{\mathrm{GC} 2}$ and of $\mathrm{PEV}_{\mathrm{AF} 1}$ and $\mathrm{PEV}_{\mathrm{AF} 2}$ respectively with the weighting dependent on the sampling variances of the component formulations. Garcia-Cortes et al. [10] suggest weighting by asymptotic approximations of the sampling variances. The sampling variances could also be approximated empirically using independent replicates of $n$ samples or by leave-one-out Jackknife procedures [13,14]. These alternative weighting strategies were compared by calculating sampling variances using 100 independent replicates of the $n$ samples, using the $n$ samples and a leaveone-out Jackknife procedure [14], and using the asymp- totic sampling variances outlined in Table 1 as part of an iterative procedure, which involved two iterations. In the first iterations the asymptotic sampling variances were calculated using the $\mathrm{PEV}_{\mathrm{GC} 1}$ and $\mathrm{PEV}_{\mathrm{GC} 2}$ of the component formulations, in the second they used the $\mathrm{PEV}_{\mathrm{GC} 3}$ approximated in the first iteration.

\section{Calculation of required variances and covariances}

It was not possible to store each of the 100,000 simulated values for each of the 50,435 animals in the main memory of the computer simultaneously meaning that textbook formulae to calculate the different variances and covariances required for the different formulations was not possible. Textbook updating algorithms to calculate the variance can be numerically unreliable [19]. Instead the required variances were calculated using a one pass updating algorithm based on Chan et al. [19] which updates the estimated sum of squares with a new record as it reads through the data and takes the form:

$$
S_{n}=S_{n-1}+\left((n-1)\left(\frac{\left[\left(T_{n-1} / n-1\right)-x_{i}\right]^{2}}{n}\right)\right)
$$

where $n$ are the number samples at any stage in the updating procedure and $T$ and $S$ are the sum and sum of squares of the data points 1 through $n$. It was modified to calculate the covariances between $\mathrm{X}$ and $\mathrm{Y}$ by changing $\left[\left(T_{n-1} / n-1\right)-x_{i}\right]^{2}$ $\left[\left(T^{x_{n-1} / n-1}\right)-x_{i}\right] \times\left[\left(T^{y_{n-1}} / n-1\right)-y_{i}\right]$. Both of these algorithms were tested using one replication of 100,000 samples and found to be stable.

\section{Results}

As the $\sigma_{g}^{2}$ was taken to be 1.0, the PEV ranged between 0.00 and 1.0. For the purpose of categorizing the results PEV with values between 0.00 and 0.33 were regarded as low, values between 0.34 and 0.66 were regarded as medium, and values between 0.67 and 1.00 were regarded as high.

Henderson [20] showed that it is much easier to form $\mathbf{A}^{-1}$ than $\mathbf{A}$, where $\mathbf{A}$ is the numerator relationship matrix among animals. This follows from the fact that, if the individuals are listed with ancestors above descendants, A can be written as TMT" where $\mathbf{M}$ is a diagonal matrix and $\mathbf{T}$ is a lower triangular matrix with non-zero diagonal ele- 


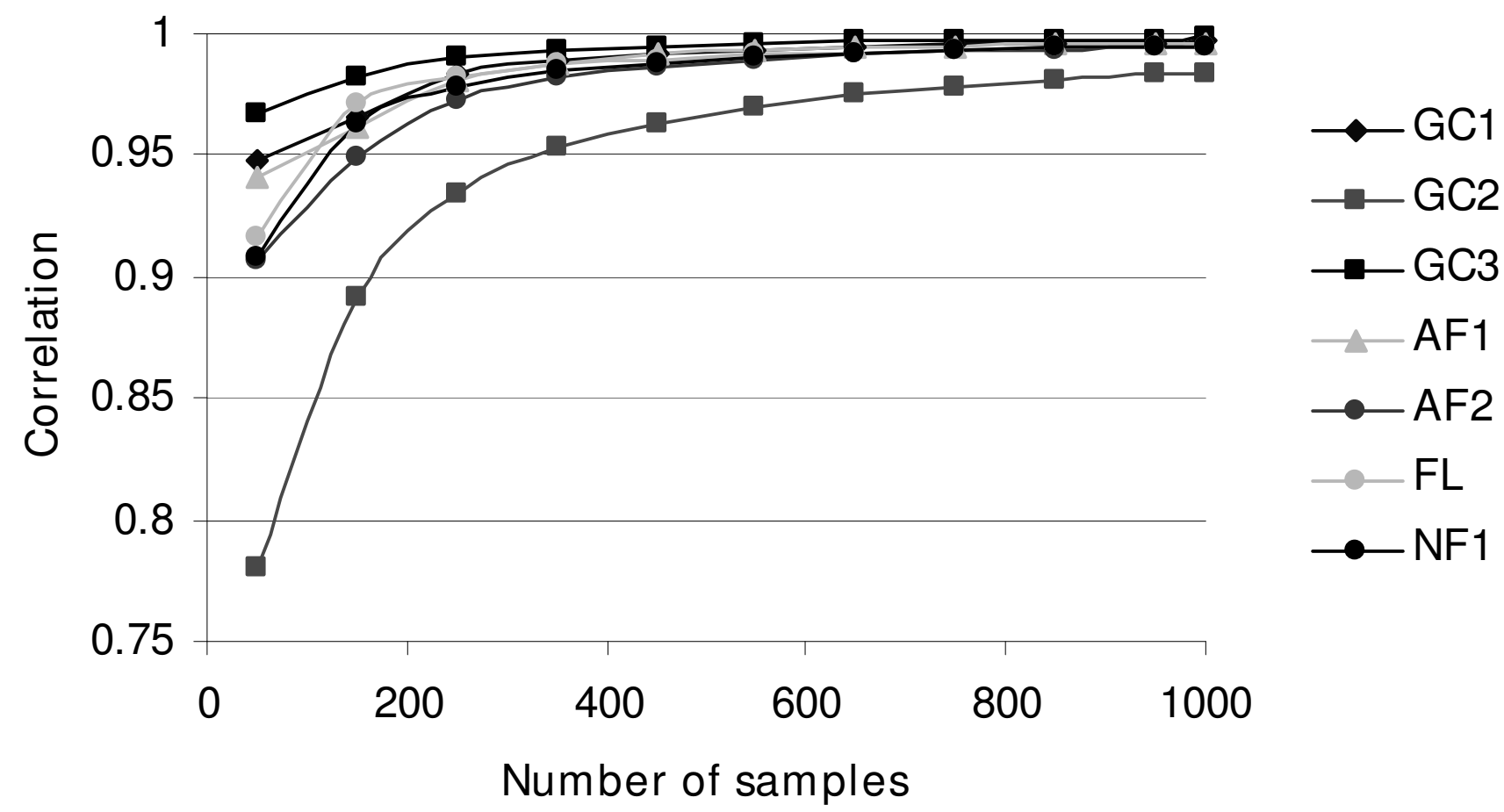

Figure I

Correlations between exact prediction error variance and different formulations of sampled prediction error variance ${ }^{l}$ using $n$ samples $(n=50,100, \ldots, 950,1000)$, for 18,855 non-inbred animals. ${ }^{I} P E V_{N F 2}, P V_{A F 3}, P E V_{A F 4}$ are not shown as they have trends, which match $\mathrm{PEV}_{\mathrm{GC} 3}$

ments and $i, j$ th elements that are non-zero if the $j$ th individual is an ancestor of the $i$ th [21]. The matrix $\mathbf{T}$ has a simple inverse with both the diagonal elements and $i, j$ th elements being non-zero if the $j$ th individual is a parent of the $i$ th individual. Hence A has a simple inverse. It is interesting to note that an animal effect can be written as an accumulation of independent terms from its ancestors $u_{i}=\frac{\left(u_{s i}+u_{d i}\right)}{2}+m_{i}$, where $u_{s i}$ and $u_{d i}$ are the additive genetic effects of the sire and dam of animal $i$ and $m_{i}$ is the Mendelian sampling effect with variance

$A_{m_{i}}=\frac{\left(1-F_{i}\right)}{2} \sigma_{g}^{2}$, where $F_{i}$ is the average inbreeding of the parents of animal $i$. Hence there is a simple recursive procedure for generation of the additive effects $u_{i}$ by generating independent Mendelian sampling terms $m_{i}$ with diagonal variance matrix $\mathbf{A}_{m_{i}}$.

\section{General trends of sampled PEV}

While all different formulations of the sampled PEV converged to the $\mathrm{PEV}_{\text {exact }}$ and the sampling variance of the PEV reduced as the number of samples $(n)$ increased, convergence rates differed between the formulations. For example, $\mathrm{PEV}_{\mathrm{GC} 2}$ converged at a slower rate than all other formulations when the convergence rate was measured by the correlation between $\mathrm{PEV}_{\text {exact }}$ and sampled PEV (Fig. 1). $\mathrm{PEV}_{\mathrm{GC} 1}, \mathrm{PEV}_{\mathrm{AF} 3}, \mathrm{PEV}_{\mathrm{AF} 4}$, and $\mathrm{PEV}_{\mathrm{NF} 2}$, all converged at a very similar rates and had the best convergence across all formulations.

As well as depending on the numbers of samples, the convergence rate also depended on the level of the $\mathrm{PEV}_{\text {exact }}$. The sampled PEV calculated using different formulations had different sampling variances and within each formulation the sampling variances differed depending on the level of the $\mathrm{PEV}_{\text {exact }}$ (Fig. 2). Of the previously published formulations $\mathrm{PEV}_{\mathrm{GC} 1}$ and $\mathrm{PEV}_{\mathrm{FL}}$ had low sampling variance at high $\mathrm{PEV}_{\text {exact }}$ with $\mathrm{PEV}_{\mathrm{GC} 1}$ being better than $\mathrm{PEV}_{\mathrm{FL}}$. $\mathrm{PEV}_{\mathrm{GC} 2}$ had low sampling variance at low $\mathrm{PEV}_{\text {exact }}$. Accounting for the effects of sampling on the $\operatorname{Var}(\mathrm{u})$ reduced the sampling variance in regions where the previously published formulations had high sampling variances but had little (or even slightly negative) effect where these formulations had low sampling variances. $\mathrm{PEV}_{\mathrm{AF} 4}$, which is the alternative version of $\mathrm{PEV}_{\mathrm{FL}}$ gave major improvements in terms of sampling variance low and intermediate $\mathrm{PEV}_{\text {exact }}$. Its performance was almost identical to $\mathrm{PEV}_{\mathrm{NF} 2}, \mathrm{PEV}_{\mathrm{AF} 3}$, and $\mathrm{PEV}_{\mathrm{GC} 3}$, which had low sam- 
A

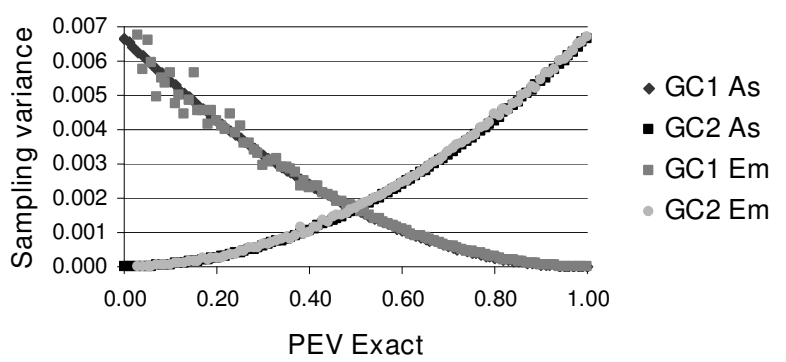

C

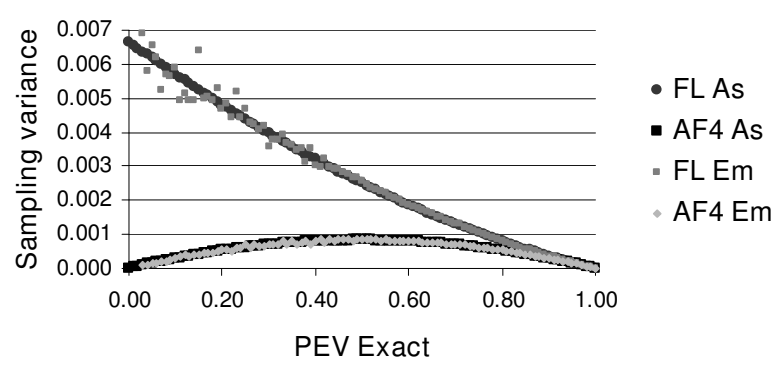

B

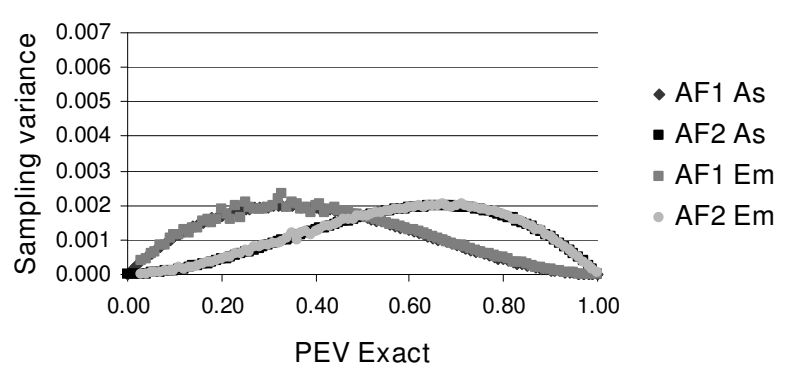

$\mathrm{D}$

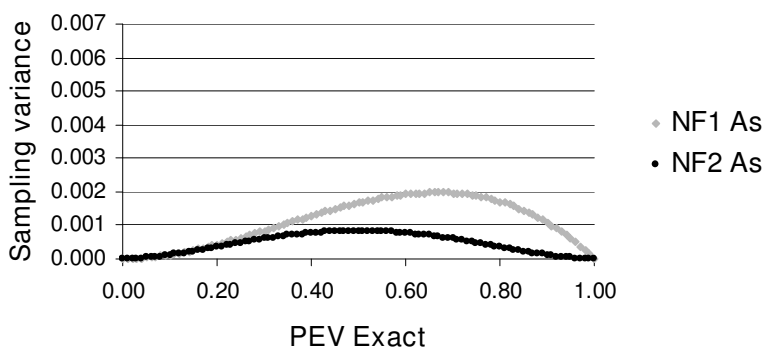

Figure 2

Sampling variances of sampled prediction error variance approximated asymptotically (As) and empirically' (Em) using different formulations of the prediction error variance using $\mathbf{3 0 0}$ samples for different levels of exact prediction error variance. (A) Sampling variances for $P E V_{G C l}$ and $P E V_{G C 2}$. (B) Sampling variances for $P E V_{A F I}$ and $\mathrm{PEV}_{\mathrm{AF2} \text {. }}$ (C) Sampling variances for $\mathrm{PEV}_{\mathrm{FL}}$ and $\mathrm{PEV}_{\mathrm{AF} 4}$. (D) Sampling variances for $P E V_{\mathrm{NFI}}$ and $\mathrm{PEV}_{\mathrm{NF2}}{ }^{2}$. 'Empirical sampling variances were approximated using 100 independent replicates and presented as averages within windows of $0.00 \mathrm{I}$ of the exact prediction error variance. ${ }^{2} \mathrm{PEV}_{\mathrm{GC} 3}$, and $\mathrm{PEV}_{\mathrm{AF} 3}$ were similar to $\mathrm{PEV}_{\mathrm{NF} 2}$.

pling variance at both high and low PEV. No formulation had relatively low sampling variance for intermediate PEV.

\section{Comparison of formulations}

Different formulations were compared in greater detail using $n=300$ samples (Table 2), which is a practical number of samples. $\mathrm{PEV}_{\mathrm{GC} 3}, \mathrm{PEV}_{\mathrm{AF} 3}, \mathrm{PEV}_{\mathrm{AF} 4}$, and $\mathrm{PEV}_{\mathrm{NF} 2}$ were the best formulations across all of the ten formulations. The slopes and $\mathrm{R}^{2}$ of their regressions were always among the best where $\mathrm{PEV}_{\text {exact }}$ was low, intermediate, or high (Table 2). These formulations gave good approximations at both high and low $\mathrm{PEV}_{\text {exact }}$ their performance was less good at intermediate PEV, measured by each of the summary statistics (Table 2).

$\mathrm{PEV}_{\mathrm{GC} 1}$ and $\mathrm{PEV}_{\mathrm{FL}}$ gave good approximations for high $\mathrm{PEV}_{\text {exact }}$ and poor approximations for low $\mathrm{PEV}_{\text {exact }} \cdot \mathrm{PEV}_{\mathrm{GC} 2}$ gave good approximations for low $\mathrm{PEV}_{\text {exact }}$ and poor approximations for high $\mathrm{PEV}_{\text {exact }}$. Improving the published formulations by correcting for the effects of sampling resulted in better approximations in areas where the published formulations were weak. Slight (dis)improvements were observed where the previously published formulations were strong. Of the new formulations $\mathrm{PEV}_{\mathrm{NF} 1}$ gave poor approximations and $\mathrm{PEV}_{\mathrm{NF} 2}$ gave good approximations.

Using the three alternative weighting strategies to combine the component formulations for $\mathrm{PEV}_{\mathrm{GC}}$ and $\mathrm{PEV}_{\mathrm{AF}}$ gave almost identical results (Table 3 ).

\section{Required number of samples}

The formulations $\mathrm{PEV}_{\mathrm{GC} 3}, \mathrm{PEV}_{\mathrm{AF} 3}, \mathrm{PEV}_{\mathrm{AF} 4}$, and $\mathrm{PEV}_{\mathrm{NF} 2}$ gave similar approximations and had the lowest sampling variance. Even when a few samples $(n=50)$ were used, 
Table 2: Intercept, slope, $\mathbf{R}^{2}$, and root mean squared error (RMSE) of regressions of exact prediction error variance on sampled prediction error variance approximated using one of 10 different formulations of the prediction error variance using 300 samples, for I 8,855 non-inbred animals

\begin{tabular}{|c|c|c|c|c|c|c|c|c|c|c|c|}
\hline & PEV $_{\text {exact }}$ & PEV $_{\mathrm{GCI}}$ & $\mathrm{PEV}_{\mathrm{GC2}}$ & PEV $_{\text {GC3 }}$ & PEV $_{\mathrm{FL}}$ & PEV $_{\text {AFI }}$ & PEV $_{\text {AF2 }}$ & PEV $_{\text {AF } 3}$ & PEV $_{\text {AF4 }}$ & PEV $_{\text {NFI }}$ & PEV $_{\text {NF2 }}$ \\
\hline \multirow[t]{3}{*}{ Intercept } & $0.00-0.33$ & 0.09 & 0.01 & 0.01 & 0.09 & 0.05 & 0.02 & 0.01 & 0.02 & 0.01 & 0.01 \\
\hline & $0.34-0.66$ & 0.26 & 0.32 & 0.17 & 0.31 & 0.27 & 0.30 & 0.18 & 0.18 & 0.29 & 0.17 \\
\hline & $0.67-1.00$ & 0.09 & 0.29 & 0.06 & 0.05 & 0.09 & 0.06 & 0.02 & 0.02 & 0.04 & 0.04 \\
\hline \multicolumn{12}{|l|}{ Slope } \\
\hline & $0.00-0.33$ & 0.62 & 0.90 & 0.93 & 0.62 & 0.77 & 0.89 & 0.93 & 0.93 & 0.91 & 0.95 \\
\hline & $0.34-0.66$ & 0.57 & 0.43 & $0.7 \mathrm{I}$ & 0.47 & 0.54 & 0.48 & 0.68 & 0.69 & 0.49 & $0.7 \mathrm{I}$ \\
\hline & $0.67-1.00$ & 0.91 & 0.67 & 0.94 & 0.95 & 0.91 & 0.93 & 0.98 & 0.97 & 0.96 & 0.96 \\
\hline \multirow[t]{3}{*}{$\mathbf{R}^{2}$} & $0.00-0.33$ & 0.65 & 0.94 & 0.95 & 0.65 & 0.76 & 0.91 & 0.95 & 0.94 & 0.93 & 0.95 \\
\hline & $0.34-0.66$ & 0.59 & 0.43 & 0.68 & 0.49 & 0.54 & 0.48 & 0.67 & 0.69 & 0.49 & 0.70 \\
\hline & $0.67-1.00$ & 0.96 & 0.64 & 0.97 & 0.97 & 0.95 & 0.90 & 0.98 & 0.98 & 0.92 & 0.98 \\
\hline \multirow[t]{3}{*}{ RMSE } & $0.00-0.33$ & 0.05 & 0.02 & 0.02 & 0.05 & 0.04 & 0.03 & 0.02 & 0.02 & 0.02 & 0.02 \\
\hline & $0.34-0.66$ & 0.03 & 0.03 & 0.02 & 0.03 & 0.03 & 0.03 & 0.02 & 0.02 & 0.03 & 0.02 \\
\hline & $0.67-1.00$ & 0.02 & 0.06 & 0.02 & 0.02 & 0.02 & 0.03 & 0.01 & 0.02 & 0.03 & 0.01 \\
\hline
\end{tabular}

low and high PEV were well approximated and intermediate $\mathrm{PEV}_{\text {exact }}$ were poorly approximated. Correlations between $\mathrm{PEV}_{\mathrm{NF} 2}$ and $\mathrm{PEV}_{\text {exact }}$ were 0.88 for low, 0.96 for high $\mathrm{PEV}_{\text {exact }}$ and 0.51 for intermediate $\mathrm{PEV}_{\text {exact. }}$ To increase the correlation for intermediate $\mathrm{PEV}_{\text {exact }}$ to at least 0.90 at least 550 samples was needed. At this number of samples the correlations for low and high $\mathrm{PEV}_{\text {exact }}$ were $\geq$ 0.99 . To obtain a satisfactory level of convergence 300 samples were sufficient.

\section{Discussion}

\section{Differences between formulations}

Ten different formulations of the PEV approximated using sampling were compared and these were each shown to converge to the $\mathrm{PEV}_{\text {exact }}$ at different rates. Within each of these formulations differences in convergence were observed at different levels of $\mathrm{PEV}_{\text {exact }} \mathrm{PEV}_{\mathrm{GC1}}$ and its corresponding alternative formulation $\mathrm{PEV}_{\mathrm{AF} 1}$ make use of information on the $\operatorname{Var}(\hat{\mathrm{u}}) \cdot \mathrm{PEV}_{\mathrm{GC} 2}$ and its corresponding

Table 3: Coefficients of regressions of $\mathrm{PEV}_{\mathrm{GC}}$ and $\mathrm{PEV} \mathrm{VF}_{\mathrm{AF}}$ (sampling variances calculated empirically) on $\mathrm{PEV}_{\mathrm{GC} 3}$ and PEV $_{\mathrm{AF} 3}$ (sampling variances calculated using Jackknife) and on $\mathrm{PEV}_{\mathrm{GC} 3}$ and $\mathrm{PEV}_{\mathrm{AF} 3}$ (sampling variances calculated asymptotically and weighting done iteratively)

\begin{tabular}{lllll}
\hline & Jackknife & \multicolumn{3}{c}{ Asymptotic } \\
& PEV $_{\text {GC3 }}$ & PEV $_{\text {AF3 }}$ & PEV $_{\text {GC3 }}$ & PEV $_{\text {AF3 }}$ \\
\hline Intercept & 0.00 & 0.00 & 0.00 & 0.01 \\
Slope & 1.00 & 1.00 & 1.00 & 1.00 \\
R $^{2}$ & 1.00 & 1.00 & 1.00 & 1.00 \\
RMSE & 0.01 & 0.00 & 0.00 & 0.01 \\
\hline
\end{tabular}

alternative formulation $\mathrm{PEV}_{\mathrm{AF} 2}$ makes use of information on the $\operatorname{Var}(\mathrm{u}-\hat{\mathrm{u}})$. The sampling variance of the $\operatorname{Var}(\hat{\mathrm{u}})$ is lower at high $\mathrm{PEV}_{\text {exact }}$ than it is at low $\mathrm{PEV}_{\text {exact }}$ (Fig. 3), therefore the formulations using information on the $\operatorname{Var}(\hat{\mathrm{u}})$ are more suited to approximating high $\mathrm{PEV}_{\text {exact }}$ than to low $\mathrm{PEV}_{\text {exact }}$. The opposite is the case for formulations which use information on the $\operatorname{Var}(\mathbf{u}-\hat{\mathrm{u}})$, they perform better at low $\mathrm{PEV}_{\text {exact }}$. Formulations $\mathrm{PEV}_{\mathrm{GC}}, \mathrm{PEV}_{\mathrm{AF} 3}$, and $\operatorname{PEV}_{\mathrm{NF} 2}$ use information on both the $\operatorname{Var}(\hat{\mathrm{u}})$ and the $\operatorname{Var}(\mathrm{u}-\hat{\mathrm{u}})$ and result in curves for their sampling variance which are symmetric about the mean $\mathrm{PEV}_{\text {exact. }}$ They either explicitly or implicitly weight this information by the inverse of its sampling variance. $\mathrm{PEV}_{\mathrm{FL}}$ and $\mathrm{PEV}_{\mathrm{AF} 4}$ make use of information on the $\operatorname{Cov}(\mathrm{u}, \hat{\mathrm{u}})$.

With infinite samples the $\operatorname{Var}(\mathrm{u})$ is equal to the $\sigma_{\mathrm{g}}^{2}$, but due to sampling error resulting from using a limited number of samples this not likely to be true in practice. Therefore each of the alternative formulations makes use of information on the $\operatorname{Var}(\mathrm{u})$ in addition to making use of information on either/or/both of the $\operatorname{Var}(\hat{\mathrm{u}})$ and the $\operatorname{Var}(\mathrm{u}-\hat{\mathrm{u}})$ or the $\operatorname{Cov}(\mathrm{u}, \hat{\mathrm{u}})$. The $\operatorname{Var}(\hat{\mathrm{u}})=\operatorname{Cov}(\mathrm{u}, \hat{\mathrm{u}})$ when the $\operatorname{Cov}((\mathrm{u}-\hat{\mathrm{u}}), \hat{\mathrm{u}})=0$. The $\operatorname{Var}(\hat{\mathrm{u}}) \neq \operatorname{Cov}(\mathrm{u}, \hat{\mathrm{u}})$ when the $\operatorname{Cov}((\mathrm{u}-\hat{\mathrm{u}}), \hat{\mathrm{u}}) \neq 0$.

\section{Competitive formulations}

Of the ten different approaches four competitive formulations, $\mathrm{PEV}_{\mathrm{GC} 3}, \mathrm{PEV}_{\mathrm{AF} 3}, \mathrm{PEV}_{\mathrm{AF} 4}$, and $\mathrm{PEV}_{\mathrm{NF} 2}$, were identi- 


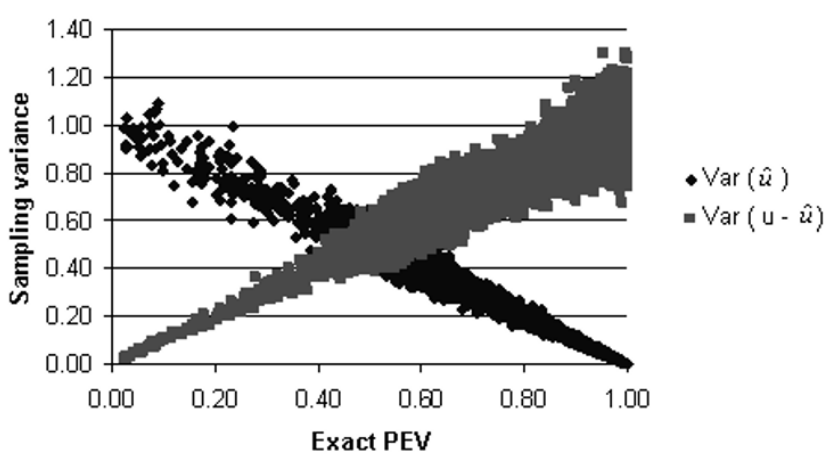

Figt $\hat{u} \geq 3$

$\hat{\mathrm{u}}$

$X-Y$ plot of the exact prediction error variance and the $\operatorname{Var}(\hat{\mathrm{u}})$ and $\operatorname{Var}(u-\hat{u})$.

fied. These gave similar approximations. Of the four, two, $\mathrm{PEV}_{\mathrm{GC} 3}$ and $\mathrm{PEV}_{\mathrm{AF} 3}$, were weighted averages of component formulations. The weighting was based on the sampling variances of their component formulations. These sampling variances can be calculated using a number of independent replicates, using Jackknife procedures, or asymptotically. Each of these approaches gave almost identical results but the Jackknife and asymptotic approaches were far less computationally demanding.

\section{Computational time}

A single BLUP evaluation for the routine Irish multiple breed beef genetic cattle evaluation (January 2007) which included a pedigree of 1,500,000 and 493,092 animals with performance records on at least one of the 15 traits could be run using MiX99 [18] in 366 min on a 64 bit PC, with a $2.40 \mathrm{GHz}$ AMD Opteron dual-core processor and 8 gigabytes of RAM [12]. Using $n=300$ samples and PEV NF2 $_{2}$ the accuracy of the estimated breeding values could be estimated in 1,830 hours on a single processor. Several samples can be solved simultaneously on multiple processors thereby reducing computer time. Nowadays PC's are available that contain two quad core 64 bit processors (i.e. 8 CPU's) and cost approximately 5,000 euro. Using six of these PC's the accuracy of estimated breeding values for the Irish data set could be estimated in less than 38.1 h.

\section{Application}

The Monte Carlo sampling approach using one of these four competitive formulations can be used to improve many tasks in animal breeding. Stochastic REML algorithms [e.g. [9]] can be improved in terms of speed of calculation using these formulations, therefore allowing variance components to be estimated using REML in large data sets. These REML formulations are usually written in terms of additive genetic effects $\mathbf{u}^{\prime} \mathbf{A}^{-1} \mathbf{u}$ and trace $\left[\mathrm{A}^{-1} \mathbf{P E V}\right]$, where PEV is the prediction error covariance matrix for the estimated breeding values. The results of Henderson [22] show how the REML formulations can be equivalently written as in terms of Mendelian sampling effects $m$ $\mathbf{m}^{\prime} \mathbf{A}^{-1} \mathbf{m}$ and trace $\left[\mathbf{A}_{\mathbf{m}}{ }^{-1} \mathbf{P E V} \mathbf{m}_{\mathbf{m}}\right]$, where $\mathbf{P E V}_{\mathbf{m}}$ is the prediction error covariance matrix for the Mendelian sampling effects. As $A_{m}$ is diagonal we see that we only need to compute the sampling variances of the Mendelian sampling terms. When the sampling was carried out in this study we, in error, did not correct the Mendelian sampling terms for inbreeding. We therefore have only reported results for non-inbred animals and think that the incorrect generation will have a minimal effect on the sampling variances, which are presented as an empirical check on the formulae. There may be circumstances where a Stochastic REML approach may be faster than Gibbs sampling and have less bias than Method R [23]. Calculating variance components using more complete data sets would facilitate a reduction in the bias of estimated variance components caused by the ignoring of data on which selection has taken place in the population [12], due to computational limitations. Calculation of unbiased accuracy of within breed [8] and across breed [12] estimated breeding values can be improved by reducing the computational time required of calculation or reducing the sampling error for a given computational time. Application of an algorithm controlling the variance of response to selection [24] to large data sets can be speeded up. The variance of response to selection is a risk to breeding programs [3], which is generally not explicitly controlled using the approach outlined by Meuwissen [24] due to the inability to generate a prediction error (co)variance matrix for large data sets.

Computational power is a major limitation of stochastic methods, particularly when large data sets are involved, however this is dissipating rapidly with the improvement in processor speed, parallelization, and the adoption of 64-bit technology, however in the meantime deterministic methods will continue to be used for large scale BLUP analysis.

\section{Conclusion}

PEV approximations using Monte Carlo estimation were affected by the formulation used to calculate the PEV. The difference between the formulations was small when the number of samples increased, but differed depending on the level of the exact PEV and the number of samples. Rescaling from the scale of $\operatorname{Var}(\mathrm{u})$ to the scale of $\sigma_{g}^{2}$ improved the approximation of the PEV and four of the 10 formulations gave the best approximations of $\mathrm{PEV}_{\text {exact }}$ thereby improving the efficiency of the Monte Carlo sampling procedure for calculating the PEV. The fewer sam- 
ples that are required the less the computational time will be.

\section{Competing interests}

The authors declare that they have no competing interests.

\section{Authors' contributions}

RT derived most of the mathematical equations. JH derived the remaining equations, carried out the simulations and wrote the first draft of the paper. RV supervised the research and mentored JH. MC and HM took part in useful discussions and advised on the simulations. All authors read and approved the final manuscript.

\section{Acknowledgements}

The authors acknowledge the Irish Cattle Breeding Federation for providing funding and data. Robin Thompson acknowledges the support of the Lawes Agricultural Trust.

\section{References}

I. Henderson CR: Best linear unbiased estimation and prediction under a selection model. Biometrics 1975, 31:423-447.

2. Patterson HD, Thompson R: Recovery of inter-block information when block sizes are unequal. Biometrika |97|, 58:545-554

3. Meuwissen THE, Woolliams JA: Maximizing genetic response in breeding schemes of dairy cattle with constraints on variance of response. J Dairy Sci 1994, 77:1905-1916.

4. Lidauer M, Vuori K, Stranden I, Mantysaari E: Experiences with Interbull Test IV: Estimation of genetic variance. Proceedings of the Interbull Annual Meeting: Dublin, Ireland 2007, 37:69-72.

5. Harris B, Johnson D: Approximate reliability of genetic evaluations under an animal model. J Dairy Sci 1998, 81:2723-2728.9.

6. Tier B, Meyer K: Approximating prediction error covariances among additive genetic effects within animals in multipletrait and random regression models. J Anim Breed Genet 2004, 121:77-89.

7. Jensen J, Mao IL: Transformation algorithms in analysis of single trait and of multitrait models with equal design matrices and one random factor per trait: a review. J Anim Sci 1988, 66:2750-276I.

8. Fouilloux MN, Laloë $D$ : A sampling method for estimating the accuracy of predicted breeding values in genetic evaluation. Genet Sel Evol 200I, 33:473-486.

9. Garcia-Cortes LA, Moreno C, Varona L, Altarriba J: Variance component estimation by resampling. I Anim Breed Genet 1992 109:358-363.

10. Garcia-Cortes LA, Moreno C, Varona L, Altarriba J: Estimation of prediction error variances by resampling. I Anim Breed Genet 1995, I I 2:176-182.

II. Thompson R: Integrating best linear unbiased prediction and maximum likelihood estimation. Proceedings of the 5th World Congress on Genetics Applied to Livestock Production: Guelph, Canada 1994, I 8:337-340.

12. Hickey JM, Keane MG, Kenny DA, Cromie AR, Mulder HA, Veerkamp RF: Estimation of accuracy and bias in genetic evaluations with genetic groups using sampling. I Anim Sci 2008 , 86:1047-1056.

13. Efron B: Bootstrap methods: another look at the jackknife. Ann Stat 1979, 7:1-26.

14. Tukey J: Bias and confidence in not quite large samples. Ann Math Statist 1958, 29:614.

15. Klassen DJ, Smith SP: Animal model estimation using simulated REML. Proceedings of the 4th World Congress on Genetics Applied to Livestock Production: Edinburgh 1990, I 2:472-475.

16. Thallman RM, Taylor JF: An indirect method of computing REML estimates of variance components from large data sets using an animal model. J Dairy Sci I99I, 74(Suppl I): 160.
17. Gilmour AR, Cullis BR, Welham SJ, Thompson R: ASReml User Guide (Release 2). VSN International, Hemel Hempstead, HPI IES, UK; 2006.

18. Lidauer M, Stranden I, Vuori K, Mantysaari E: MiX99 User Manual MTT, Jokioinen, Finland; 2006.

19. Chan TF, Golub GH, LeVeque RJ: Algorithms for computing the sample variance: analysis and recommendations. Am Stat 1983, 37:242-247.

20. Henderson CR: A simple method for computing the inverse of a numerator relationship matrix used in prediction of breeding values. Biometrics 1976, 32:69.

21. Thompson R: Sire evaluation. Biometrics 1979, 35:339-353

22. Henderson CR: Applications of Linear Models in Animal Breeding Guelph, Ontario, Canada, University of Guelph; 1984.

23. Reverter A, Golden BL, Bourdon RM, Brinks JS: Method R variance components procedure: application on the simple breeding value model. J Anim Sci 1994, 72:2247-2253.

24. Meuwissen TH: Maximizing the response of selection with a predefined rate of inbreeding. J Anim Sci 1997, 75:934-940.
Publish with Bio Med Central and every scientist can read your work free of charge

"BioMed Central will be the most significant development for disseminating the results of biomedical research in our lifetime. "

Sir Paul Nurse, Cancer Research UK

Your research papers will be:

- available free of charge to the entire biomedical community

- peer reviewed and published immediately upon acceptance

- cited in PubMed and archived on PubMed Central

- yours - you keep the copyright
BioMedcentral 